\title{
Contexto moral cultural y biológico en las familias e instituciones educativas de los superdotados
}

\author{
Moral, cultural and biological context in the families and educational institutions of the gifted
}

Contexto moral, cultural e biológico nas famílias e instituições educacionais dos superdotados

\section{Zila Isabel Esteves Fajardo \\ zila.estevesf@ug.edu.ec \\ https://orcid.org/0000-0002-2283-5370}

Universidad de Guayaquil, Guayaquil-Ecuador

Karina Cecibel Arcos Cárdenas

karina_arcos78@hotmail.comhttps://orcid.

org/0000-0002-8069-5820

Universidad de Guayaquil, Guayaquil-Ecuador

\section{Guadalupe Elizabeth Paredes Menéndez \\ guadalupe.paredesm@ug.edu.ec \\ https://orcid.org/0000-0003-0125-9025}

Universidad de Guayaquil, Guayaquil-Ecuador

Rita Carolina Eguez Cevallos

rita.eguezc@ug.edu.ec

https://orcid.org/0000-0003-0226-3026

Universidad de Guayaquil, Guayaquil-Ecuador

Artículo recibido en junio 2021, revisado en julio 2021, arbitrado en agosto 2021, publicado en septiembre 2021

\section{RESUMEN}

La presente investigación tuvo como objetivo diagnosticar aspectos del contexto moral, cultural y biológico que inciden en la superdotación de niños mediante un estudio de campo para recomendar el respeto a las necesidades educativas especiales de quienes poseen ese parámetro intelectual. Es una investigación descriptiva y exploratoria Se realiza para una población de 20 docentes, 5 padres que narran la convivencia con sus hijos con superdotación y 4 niños de escuelas de la ciudad de Guayaquil. La población de estudiantes estuvo entre los 8 a 12 años de la EGB y con resultados como son que la vida familiar de madres entre los 30 a 40 años influye en el desarrollo del potencial superdotado. Como conclusiones se encuentran indicadores en que la genética biológica y cultural, inciden en la calidad de las familias en que los niños superdotados tienen durante su infancia, y los años de estudio de la Educación Básica.

Palabras clave: Contexto moral; educación especial; Superdotadosesfuerzo personal; Embarazo
ABSTRACT

The objective of this research is to diagnose aspects of the moral, cultural and biological context that affect the giftedness of children through a field study to recommend respect for the special educational needs of those who possess this intellectual parameter. It is a descriptive and exploratory research. It is carried out for a population of 20 teachers, 5 parents who narrate the coexistence with their gifted children and 4 children from schools in the city of Guayaquil. The student population was between 8 to 12 years of EGB and with results such as that the family life of mothers between 30 to 40 years influences the development of gifted potential. As conclusions, there are indicators that biological and cultural genetics affect the quality of families in which gifted children have during their childhood, and the years of study of Basic Education.

Key words: Moral context: special education; gifted; personal effort; pregnancy

\section{RESUMO}

O objetivo desta pesquisa é diagnosticar aspectos do contexto moral, cultural e biológico que afetam a superdotação de crianças por meio de um estudo de campo para recomendar o respeito às necessidades educacionais especiais de quem possui esse parâmetro intelectual. Trata-se de uma pesquisa descritiva e exploratória, realizada para uma população de 20 professores, 5 pais que narram a convivência com seus filhos superdotados e 4 crianças de escolas da cidade de Guayaquil. A população estudantil encontrava-se entre 8 a 12 anos de EGB e com resultados como que a vida familiar das mães entre $30 \mathrm{a}$ 40 anos influencia no desenvolvimento do potencial superdotado. Como conclusões, há indicadores de que a genética biológica e cultural interfere na qualidade das famílias que as crianças superdotadas têm durante a infância, e nos anos de estudo da Educação Básica.

Palavras-chave: Contexto moral; educação especial; dotado; esforço pessoal; gravidez 


\section{INTRODUCCIÓN}

Durante el desarrollo de la superdotación existen una serie de aspectos que hay que saber interpretar con la finalidad de valorar el talento humano nacional desde la infancia y evitar malos resultados de algo tan importante en la vida de la sociedad.

Landau (2002) expresa lo siguiente:

La atmósfera emocional en la que crece un niño, tiene que darle seguridad y libertad para que pueda atreverse a mostrar sus talentos y ampliar el círculo de su mundo, a veces estrecho, y a pisar terreno nuevo (p. 29).

Al ubicar a los niños en esa parte de la población de estudiantes, son los docentes, los que con la ayuda de los representantes legales y del Departamento de Consejería Estudiantil (DECE), han permitido conseguir una serie de indicadores que van a permitir situar a estos estudiantes en correspondencia con su talento y, de esta manera, promover su extremo cuidado. La propuesta es permitir que aquellos estudiantes a los que se les ha descubierto la superdotación sepan manejarse, de manera adecuada, y logren el desarrollo de sus talentos, por medio de la inversión de tiempo por parte del Estado o los municipios, tanto a los que sobresalen como a los que tienen deficiencias marcadas por la influencia familiar. Por lo que aparece una interrogante problemática: ¿qué influencia tiene el contexto familiar y escolar en el desarrollo de las potencialidades en los niños con superdotación?

Las dudas surgen en los padres y docentes de manera continua cuando se trata de la presencia de hijos o estudiantes que se diferencian de sus otros hijos, o aquellos que a pesar de haber sufrido muchos problemas- según ellos- no han podido desmayar hacia sus objetivos, sino que se han podido superar la realidad o mejorarla. El problema reside en el poco conocimiento que se haga con relación a la superdotación intelectual a pesar de que son ya muchos años del descubrimiento de estos grupos minoritarios. Identificar a estos niños desde los primeros años debe constar en el récord del DECE al menos como sospecha de superdotación, sin que esto involucre penalizar a quienes dan ese diagnóstico.

Dicho análisis trata de unir dos elementos epistemológicamente importantes, la herencia biológica y el contexto familiar para tener claras las ideas de porqué los niños superdotados mantienen una conducta y un aprovechamiento que los ubica dentro del grupo de las necesidades educativas especiales y por otro a estudiantes que teniendo familias con poca asertividad y mala comunicación, luchan por sobrevivir en la parte educativa, y se pone en riesgo el talento humano.

Este estudio planteó como objetivo general descubrir la influencia familiar y la edad de los padres durante el embarazo de las madres de los niños superdotados interrogándolas sobre los antecedentes familiares y personales para elaborar un conjunto de indicadores asociados a la superdotación.

Al respecto, es importante explicar que el estudio ha permitido afirmar que la utilidad de las verdades que existen en el aula, son necesarias conocerlas para abordar con sentido científico aspectos tan cruciales como son los pedagógicos, en los que está comprometido el futuro del niño, de su familia, de su ciudad y país. Además son los países los que se fortalecen con estos seres que conviven en contextos culturales y educativos, pero que pueden perder la categoría de útiles y de servicio a la comunidad sino se los encausa correctamente. 
En atencion a lo antes planteado, relacionando la herencia biológica con la herencia cultural, es necesario destacar que en el embarazo de las madres de niños superdotados, ellas lo han llevado mejor con la ayuda de elementos externos como la música.

Por eso es importante contestar a la siguiente pregunta: ¿Cuál es el contexto moral y cultural que incide en la superdotación positiva o negativa que conviven en familias e instituciones educativas?

Se destaca, en el marco del contexto cultural, el lenguaje como un rasgo particularmente relacionado con la superdotación. El razonamiento verbal, la comprensión y la expresión lingüística son un signo de inteligencia alta. Así, para Rodríguez Caso y Cruz Castañeda (2016) expresan que el ser humano es un tema de discusión que reviste de mayor complejidad con respecto a otros organismos.

Adicionalmente, al contrastar con el origen académico de los padres, gran parte de la agilidad en la verbalización, la adquieren de ellos, así mismo en la variedad tecnológica, de los padres que mantienen títulos como ingeniería, algunos de los superdotados muestran relación directa con el apego paterno o materno derivado del uso continuo de las matemáticas por los padres y su predisposición para la enseñanza a temprana edad a sus hijos; pero no es sólo el título lo que acompaña a la superdotación.

Para Paba Barbosa et al. (2020) el estudio de la superdotación intelectual implica el análisis de diversas aproximaciones al término, partiendo de los modelos teóricos que se han formulado desde los inicios de la psicología de la inteligencia (p.53).

También asevera que "si los procesos de identificación resultan ser necesarios para el desarrollo de programas de atención a estudiantes con altas capacidades, entonces es mucho más pertinente formular propuestas que favorezcan la atención desde las primeras etapas del ciclo vital". (p. 87).
Para atender esta situación los autores del presente estudio se planteó la necesidad diagnosticar aspectos del contexto moral y cultural que inciden en la superdotación positiva o negativa de niños mediante un estudio de campo de los padres e instituciones educativas para recomendar el mejoramiento del contexto educativo en niños destacados pero con problemas desde sus familias.

La relevancia de la investigación radica en el debate que esta problemática genera en distintas áreas de la sociedad actual, a fin de entender la complejidad del universo de los niños superdotados en un contexto cultural dinámico, heterogéneo y crítico. Además de presentar una visión humana y con un sentido amplio de lo que implica ahondar en los actores de esta temática educativa, cargada múltiples consideraciones.

\section{Consideraciones fundamentales}

El conductismo en su momento aceptó la superdotación y el constructivismo también lo puede medir mediante el desempeño de estudiantes que mantienen su aporte al grupo y su demostración de saberes a pesar de que trabajan entre varios. La discriminación es un factor que existe en esta problemática. Por lo tanto, si estos valores no se trabajan desde edades tempranas será difícil que también las actitudes de las siguientes generaciones (Jiménez de la Hoz, 2019).

De allí cobra importancia que un superdotado puede desarrollar muy bien sus facultades en escuelas donde los maestros carecen de una visión constructivista, pero cuando los docentes lo practican, a través de su creatividad, espontaneidad y su predisposición al trabajo de grupo, dan paso a lo que se llamará aquí: "inteligencia colaborativa".

González y Váttimo (2012) expresan al respecto lo siguiente: 
Los procesos creativos-productivos, la construcción social del conocimiento y la inteligencia desplegada a partir de las interacciones personales, resultan un campo de interés en el estudio de las funciones cognitivas superiores. Nacen así conceptos novedosos como inteligencia emergente, inteligencia colectiva e inteligencia colaborativa. (s.n.)

Pues esas inteligencias que más llaman la atención en clases deben ser conocidas por los docentes, de lo contrario se convierten en un entramado de problemas con pocas alternativas de resolución efectiva. Para Pérez Lujan, González Morales, y Díaz Alfonso (2020) "como problema psicológico el estudio del talento se considera con justeza uno de los de más difícil análisis” (p. 2).

Como la existencia de superdotados es de apenas $0,001 \%$ solo el $0,010 \%$ de los docentes mantendrían entre sus aulas a aquellos. Paba Barbosa et al. (2020) consideran que el Instituto Merani, institución pionera en la atención de estudiantes con capacidades excepcionales, estima unos doscientos mil niños y jóvenes superdotados y un millón con talentos especiales solamente en Colombia.

\section{MÉTODO}

Con el propósito de dar respuesta al objetivo propuesto dentro de esta investigación la misma fue desarrollada desde un enfoque cualitativo, bajo un diseño descriptivo, pues detalló la vivencia de los niños y madres de familias que tuvieron rasgos de superdotación de parte de algunos de sus hijos.

El procedimiento de la investigación se llevó a cabo a través de fases.
En la primera, la información se obtuvo a partir de la búsqueda de libros y revistas, que en su momento se aproximaban al problema. La interpretación de los textos permitieron conocer más sobre el embarazo y su relación con las dificultades, el aprendizaje cooperativo, sus dimensiones, sus puntos de vista y descubrir cómo en otras partes del mundo se solucionaban los problemas que la población tenía.

En la segunda fase de la investigación, se seleccionó a partir de la inducción a 20 docentes de diferentes escuelas de la ciudad de GuayaquilEcuador que dieron su criterio y experiencias profesionales, a 5 madres de familia y 4 niños con superdotación.

En la tercera fase de la investigación, en la demostración y alcance del objetivo, se lograron diseñar preguntas que luego se transformaron en la encuesta a los docentes, las mismas que fueron medidas según cada respuesta. Las madres colaboraron con la elaboración de una memoria familiar, desde su embarazo hasta la actualidad, en la que destacaron las características prenatales del producto, la convivencia desde los 0 a 180 días de nacidos y luego hasta la preescolaridad y la escolaridad.

Al ser la muestra muy reducida y los niños superdotados pocos, se recurrio al DECE y a los docentes para que expresen las características de los niños que tenían signos representativos de superdotación. Una vez seleccionada la muestra las investigadoras del presente estudio se comunicaron con las madres de familia, quienes elaboraron una memoria familiar, maternal y la de los niños seleccionados. 


\section{RESULTADOS Y DISCUSIÓN}

Sobre la base del propósito de la investigación, lo hallazgos expresan que la mayoría de los superdotados son sociables, algunos muy callados, otros capaces de llamar la atención al resto, pero la constante que se descubre es que en el $90 \%$ de los casos, mantienen un comportamiento de respeto ante la autoridad y sus compañeros, situación que demuestra una influencia social y una satisfacción personal frente a la realidad que viven a diario.

Por otra parte, resulta que una posibilidad de identificación temprana es buscar a niños en la descendencia de adultos identificados como superdotados. ¿Se puede perder la superdotación como producto social? Pues socialmente sí, aunque los genes estén intactos en potencia, el contexto moral, cultural y biológico incide en la naciente inteligencia emocional de los niños.

Otro aspecto que se destaca de la investigación es la importante reflexión sobre la evolución de los niños por diferentes etapas hasta llegar a ese estado de demostración de la superdotación: a) embarazo, b) la familia c) los primeros años d) educación primaria. Si una de estas fases fallas, la calidad biológica sigue, pero no se desarrolla con la magnitud que significa ayudar a la estructura biológica de los niños, como son la alimentación, y el contexto moral con la alegría fruto de la satisfacción de sentirse querido, la sonrisa, el cariño y su afán investigativo en la fase intelectual.

En el presente estudio, el $70 \%$ de ellos tienen padres que trabajan, ambos progenitores, descartando la idea de que el exceso de control crea superdotados, cuando hay una independencia respetuosa marcada en ellos, siendo el ejemplo laboral de los padres más influyente que el control parenteral o de los abuelos. El 30\% de los superdotados mantienen una realidad familiar en que trabaja solamente uno de los padres.
Un alto porcentaje de niños superdotados tiene fracaso escolar, muchas veces por la falta de comprensión, tanto de padres como de la comunidad sobre sus facultades y aficiones que se salen del común denominador. Incluso el sistema educativo al tener en su repertorio las competencias básicas tan encapsuladas permite que el docente no cualifique o califique competencias individuales, culpándoselo muchas veces de preferencias o disgustos para un niño o de acoso por parte de otros al querer abordar a estudiantes para indicar formas particulares de seguir rutas para encontrar ciertos resultados.

Para poder establecer los resultados del análisis de los indicadores biológicos y familiares se los ha dividido en análisis del embarazo, los primeros años de los niños superdotados, cómo se ha desarrollado la instrucción primaria, el contexto familiar. A partir de ese análisis se utiliza el método inductivo para el interrogatorio y el deductivo para la determinación de los procesos.

Se ha hecho un seguimiento de 4 estudiantes de primaria, y a 10 docentes de Educación primaria de la ciudad de Guayaquil.

\section{El embarazo de las madres de los superdotados}

El 75\% de las madres de los estudiantes tuvieron un embarazo entre 34 a 38 semanas, solo uno llegó a 40 semanas de gestación, de sexo masculino. La edad de embarazo promedio es de 30 años y el número del embarazo la media aritmética es de ser el segundo embarazo. Solo uno fue de primer embarazo.

La mayoría fueron embarazos complicados, solo el que llegó a la semana 40 ese embarazo no lo fue.

La fuente de la información tiene una relación directa con lo que se declaró en la metodología. Para el diagnóstico del problema fue útil el trabajo diario 
con los estudiantes y toda la comunidad educativa que sirvió de referencia. Así se logró descubrir que la problemática estaba relacionada con la forma de convivir y el condicionamiento desde el embarazo y la concepción, con la didáctica de las madres sobre todo, y la pedagogía en las aulas, el tipo y calidad de inteligencia emocional y social de los estudiantes se ha desarrollado sin muchos problemas.

Zoe es una niña que nace con un embarazo de poco riesgo, con 35 semanas con una madre de 32 años, siendo la segunda entre los embarazos de la madre, con una sospecha de algún método de control de la concepción, luego que la madre queda embarazada de Zoe, luego de 10 años de su primer hijo.

La segunda muestra fue Allan, quien nace como fruto del tercer embarazo de su madre. La madre estuvo con asma durante el embarazo, y ante el alto riesgo, recibió medicación restringida por el mismo estado, altas cantidades de vitaminas, las cuales pudieron ser un factor favorable que ayudó a Allan. El nació a las 38 semanas de gestación, con $50 \mathrm{~cm}$ de largo, y 3.200 gramos de peso.

La tercera muestra es de sexo femenino, Dana como segunda hija con un peso de 3.100 gr., y 30 $\mathrm{cm}$., de longitud.

Posteriormente se estudió a Marcos, quien fue fruto de una relación con 3 años de matrimonio y cuya madre lo dio a luz a las 40 semanas de embarazo, con un peso de 4.900 gr. Es el primer hijo.

En cuanto a los indicadores familiares durante el embarazo o luego, se tiene que a Zoe, la madre le cantaba canciones durante el embarazo. Su canción preferida era "Yo te esperaba".

El caso de Allan, su madre también, a igual que Zoe, le cantaban durante el embarazo, y su preferencia era la música clásica.

A Dana, durante el embarazo de su madre, se movía de un lado al otro, y también la madre conversaba con ella durante el embarazo. Esta última acción conversacional fue el primer gran indicador. Al $75 \%$ de los niños superdotados, sus madres han conversado con ellos durante el embarazo.

El caso de Marcos fue un embarazo estable, sin malestar.

La segunda sección del análisis fue la de cómo les fue a los niños durante los primeros años de vida en la etapa pre escolar.

Zoe era extremadamente delgada los primeros años de su vida, con una gran sonrisa y gritona, según la describe su madre:

Y escuché su llanto y la grata noticia de que estaba bien y no necesitaría de ningún cuidado especial super delgadita pero sana gracias a Dios. Desde aquel día la vida para mí y mi familia cambió. Pasaron los días ella crecía y con su sonrisa alegraba nuestros días era muy gritona y juguetona, comenzó a balbucear palabras a los 6 meses y a dar pasos sola a los 11 meses, aunque caminó sola al primer añito le gustaba correr mucha cosa q hizo q se callera y en dos ocasiones tuvo $q$ ir al hospital la primera se partió su frente en la segunda su barbilla.

A Allan, los primeros años de vida, su madre hace la siguiente descripción:

Allan nació a las 38 semanas de gestación, nació de $50 \mathrm{~cm}$ de largo y con $3200 \mathrm{~g}$ más o menos. A sus 2 años fue circuncidado siendo ingresado en el Hospital del IESS, saliendo todo en buen estado y con una recuperación exitosa. Desde pequeño fue un niño super inquieto y muchas veces de mal genio, empezó a caminar a sus 10 meses de edad, jugaba mucho en el piso y captaba todo super rápido. A sus casi 4 años empezó la Escuela. 
A Dana, hermana de Allan, su madre, la describe así:

Niña que vino con su horario cambiado ya que se quedaba despierta y conversando hasta las 3 o 4 am; por lo que tuvimos que adaptarla al horario real. A los casi 2 meses de nacida tuvimos la necesidad de darle fórmula, pero con el pasar de los días le afectó a su salud ya que se le presentó Enterocolitis y por ese motivo fue ingresada en el Hospital del Niño Alejandro Mann donde estuvimos 7 días, con la ayuda de los doctores y la voluntad de Dios salimos adelante y se recuperó. Siempre fue una niña muy despierta, activa, inteligente y cariñosa. Empezó a subir poco a poco de peso, siendo siempre sana, hasta que, al cumplir sus 3 añitos, de nuevo nos tocó ingresar al mismo hospital, pero esta vez era por una posible Neumonía. Nuevamente salimos victoriosos de la enfermedad. Desde entonces no hemos vuelto a los ingresos hospitalarios. Danna fue creciendo independiente y activa, a sus 3 años con mucho entusiasmo ingresó a la escuela.

Luego fue analizado la vida de Marcos durante los primeros años de vida, que la madre lo describe así:

Los doctores que visitaban nuestra habitación me decían que parecía un bebe de 3 meses por su tamaño y peso. Desde muy temprana edad Marcos notaba el interés por descubrir cosas y por aprender. Sus primeros pasos los hizo a sus 10 meses de edad, posteriormente a unos días de haber estado hospitalizado por 8 días por presentar un cuadro de gastroenteritis. Al parecer el salió del hospital fortalecido y con ganas de ya caminar. En el año 2013, a sus 3 añitos nació su hermana Doménica fue en ese mismo año que él entro a la escuela a cursar su inicial 1.

En cuanto a cómo pasaron los primeros años de la Educación primaria, se obtuvo también una referencia de parte de los padres quienes conocen la historia de sus hijos. La madre de Marcos, relató que

En el año 2013, a sus 3 añitos nació su hermana Doménica fue en ese mismo año que él entro a la escuela a cursar su inicial 1 en la unidad educativa Coronel Luciano Coral, desde su inició a la etapa escolar le ha gustado interactuar con amiguitos y maestra, se ha destacado en sus calificaciones, alguna que otra vez ha hablado en público sin problema alguno, tiene buena retentiva y facilidad de palabra, en lo que es baile no le gusta pero si lo ha hecho cuando se lo han asignado.

De Zoe, su madre refiere que:

A sus tres añitos fue por primera vez a la escuela al inicial 1 en la unidad Pedro Fermín Cevallos que quedaba justo a la vuelta de nuestra casa, estaba un poco nerviosa pero no lloro y se quedó con su mirada inquieta comenzó la gran aventura de estudio en donde se ha desempeñado muy bien le gusta mucho. Es una niña super inteligente le gusta aprender, preguntar si no sabe algo. Luego a 2do. de inicial fue a la Unidad Educativa Coronel Luciano Coral en donde se ha destacado como buena alumna ha recibido diplomas $x$ ser una buena alumna y se muy dedicada a sus estudios le gusta participar al principio le daba un poco de miedo escénico ahora 
ya lo ha superado. Al comenzar su $3 e r$. Grado tuvimos q adaptarnos a la nueva forma de estudio juntas desde casa con el apoyo inmenso de su maestra lo supero y ahora le va super bien le gusta ayudar a los demás, juega, conversa, también es una niña muy dulce en sus 8 años es super especial.

La madre de Dana relata que:

Danna fue creciendo independiente $y$ activa, a sus 3 años con mucho entusiasmo ingresó a la Escuela y como teníamos pensado, ella muy inteligente en sus aprendizajes, siendo una niña curiosa e investigadora, destacó en su aula y ayudó a sus compañeritos; recuerdo que usualmente hacía preguntas tras preguntas hasta quedar conforme con la respuesta; ha sido hasta la actualidad una excelente estudiante tanto así que siempre tiene su mérito con los diplomas. En ella ha ido despertando la curiosidad, la investigación, el desenvolverse de una u otra cosa y sólo cuando lo ve necesario; pedir ayuda. En estos últimos tiempos hemos aprendido juntas a estudiar en casa con ayuda de su Maestra y le ha ido muy bien ya que los años anteriores al de antes de la pandemia, ha tenido maestras exigentes, y eso le ha ayudado a trabajar a presión en el ámbito educativo. En el ámbito familiar y social es una niña muy colaboradora y carismática, siempre dice que sí a todo lo que ella pueda ayudar."

\section{Discusión}

Se tienen dos ámbitos el intelectual y el emocional. En los niños superdotados, han sido desarrollados de manera correcta por los padres y docentes desde el embarazo. Ninguno de ellos ha tenido dificultades para el juego, pero solo al 25 $\%$ le gusta el baile como gusto estético y dinámico en sí, pero socialmente si lo hace, aunque por las exigencias del medio y no por su inclinación natural.

La educación emocional cobra más importancia en relación a las personas con diversidad funcional, debido a que deben hacer frente a situaciones emocionalmente complejas, las cuales han de superar, y donde la educación emocional les aporta una serie de herramientas que le posibilitan diferentes técnicas para poder hacer frente a dichas situaciones de manera adecuada. (Moreno Molina y Villalba Delgado, 2020, p.25).

He aquí las características de estos niños por etapas:

Los primeros años:

- Hablar y cantar mucho

- Algunos delgados

- Sonrientes y gritones

- Comienzan a hablar a los 6 meses

- Comienzan a caminar a partir de los 10 u 11 meses

- Super inquietos y a veces mal genio.

- Captan rápido la idea de los mensajes.

- Les gusta el dibujo.

- Superan las adversidades del medio.

- Muestran interés por descubrir cosas y aprender. 
Por otra parte Landau (2002) expresa que:

El enseñar y aprender no deben ser percibidos como lo contrario del juego, sino que deben incluir el juego y sus reglas. De esta forma, el nilo tendrá el valor suficiente para aceptar también algún resultado decepcionante cuando experimenta y para empezar de nuevo. (p. 29).

Ante esa realidad del juego en el aula, el niño disfruta, pero cuando el contexto familiar de que un superdotado que convive con un padre alcohólico o político millonario corrupto, quiere desarrollar sus facultades, pero no puede. Luego cambia de familia a sus 16 años con una familia con disciplina y ánimos, y ¿podrá desarrollar sus facultades? Las emociones, además de facilitar la adaptación del individuo al entorno físico, posibilita la acomodación a su entorno social. Suberviola (2020).

El capricho familiar de padres sustitutos o esposos de las madres que no son sus padres puede inhibir a un niño superdotado. Las personas con un Coeficiente Intelectual entre 120 y 130 se consideran brillantes, con una inteligencia superior, y a partir de 130 puntos se puede hablar de Superdotación Intelectual. A esa superdotación intelectual, las familias analizadas demuestran una superdotación moral y afectiva que les permite a los niños entrar confiados en sus tareas escolares. Sin esa ayuda familiar o estatal queda en el aire su capacidad de aporte a la sociedad con sus inventos y logros.

Entre las características que el grupo analizado mostró ya en sus estudios de primaria, se tiene:

- Comenzar sus estudios de preescolar a los 3 o 4 años.

- Primeros días de clase temerosos, pero poco a poco ceden ante el miedo escénico.
- Miradas inquietas.

- Les gusta aprender

- Preguntas continuas para satisfacer su ansía de conocimiento.

- Les gusta participar.

- Superan los problemas cuando les ha costado adaptarse.

- Les ha gustado la música.

- Activos, inteligentes

- Cariñosos

- Curiosos

- Investigadores

- Destacados en sus calificaciones

- Interactúan con amigos y docentes.

- Hablan en público sin problemas

- Facilidad de palabra

- No les gusta el baile

Como crítica necesaria de esta discusión se debe expresar que el niño puede perder la superdotación por falta de recursos económicos o al quedar huérfano. Uno de ellos puede quedar potencialmente negativo, siendo el Estado a través del DECE, el que debe tener la obligación de informar al Estado de esa realidad.

\section{CONCLUSIONES}

A partir de los resultados el contexto familiar de los padres incide en el desarrollo de la potencialidad de los niños superdotados. En la vida intrauterina influye el sistema simpático de la madre asociado a la neurorealidad como el mensaje de las canciones de los hermanos y de la madre durante los meses 
que aportó con una sensación de bienestar desde el vientre.

En el interrogatorio por elaboración de memorias familiares y encuestas. No se observaron embarazos de stress familiar ni de pareja, así como tampoco consumo de alcohol, drogas de ninguno de los padres de las muestras observadas durante cerca de 3 años, pero intervenidas tres meses en forma directa.

Los tres primeros años de vida son influenciados por la herencia de los padres, el control de enfermedades, el micro clima afectivo familiar, sobre todo de los hermanos y la madre.

Durante los primeros años de preescolaridad y escolaridad, el cuidado y observación de los docentes no percibieron afasias, ni de disortografía, dislexia, se encontró en ellos gran poder conversacional con un léxico adaptado a su edad, ni muy especializado, sino natural. Se mantiene la predilección por la naturaleza o el ecosistema en la mayoría de ellos, es decir la predilección por el aire libre y el juego entre amigos de la misma edad.

Estos grupos mantienen un continuo desempeño óptimo que se caracteriza por la presencia de inteligencias diferentes a la de los demás tanto en lo intelectual como en lo afectivo.

La mayoría de los docentes que los conocen de cerca piensan que ellos pueden mejorar en una escuela de superdotados. El 90\% de ellos tienen predilección por las artes, con ello se deslinda el criterio de que porque son superdotados por ejemplo en matemáticas, no guarden cierta afinidad con artes como la música, el diseño.

\section{REFERENCIAS}

González, F., y Váttimo, S. (2012 ). Procesos de la inteligencia colectiva y colaborativa en el marco de tecnologías web 2.0. Anuario de investigaciones vol. XIX, 273-281

Jiménez de la Hoz , M. C. (2019). Las personas con discapacidad intelectual en afectividad $y$ sexualidad. Madrid: Universidad Autónoma de Madrid

Landau, E. (2002). El valor de ser dotado. Madrid: Ministerio de Educación Cultura y Deporte

Moreno Molina, D., y Villalba Delgado, Y. A. (2020). Emotional education in people with functional diversity. Revista Internacional de Apoyo a la Inclusión, Logopedia, Sociedad y Multiculturalidad. Volumen 6, Número 1, 25- 33

PérezLujan, D., González Morales, D., yDíaz Alfonso, Y. (2020). El talento: antecedentes, modelos, indicadores, condicionamientos, estrategias y proceso de identificación. Una propuesta desde la Universidad cubana y el enfoque histórico cultural. Revista Iberoamericana de Educación

Rodríguez Caso, J. M., y Cruz Castañeda, P. (2016 ). Determinismo biológico y multiculturalidad: perspectivas de la moralidad . Revista digital universitaria

Suberviola, I. (2020). Aspectos básicos sobre el concepto y puesta en práctica de la coeducación emocional. Foro de Educación, 189- 207 